\title{
Energy Efficiency of a Greenhouse for the Conservation of Forestry Biodiversity
}

\author{
Alvaro Marucci, ${ }^{1}$ Maurizio Carlini, ${ }^{1}$ Sonia Castellucci, ${ }^{2}$ and Andrea Cappuccini ${ }^{1}$ \\ ${ }^{1}$ DAFNE, University of Tuscia, Via San Camillo de Lellis s.n.c., 01100 Viterbo, Italy \\ ${ }^{2}$ CIRDER, University of Tuscia, Via Cavour 23, 01028 Orte, Italy \\ Correspondence should be addressed to Alvaro Marucci; marucci@unitus.it
}

Received 21 August 2012; Accepted 1 November 2012

Academic Editor: Carlo Cattani

Copyright (c) 2013 Alvaro Marucci et al. This is an open access article distributed under the Creative Commons Attribution License, which permits unrestricted use, distribution, and reproduction in any medium, provided the original work is properly cited.

\begin{abstract}
Forest biodiversity conservation is one of the most interesting and crucial problems in forestry world. Currently, the conservation methods are based on two phases: the conservation of seeds at low temperatures and the multiplication of vegetable material. This latter operation can be successfully developed in properly designed greenhouses. The aim of this paper is to define a type of greenhouse which is particularly suitable for plant material propagation in order to preserve forest biodiversity in the area of the Central Italy. Some general parameters were first defined for a correct planning of the structure, such as: the shape of the section, volume, cover material, systems for heating and cooling, and those for the control of the internal microclimate parameters (light, air temperature, and relative humidity). Considering the construction characteristics and the climatic conditions of the place, the internal microclimatic conditions have been later determined by the useful implementation in TRNSYS in order to analyse the energy efficiency of the greenhouse.
\end{abstract}

\section{Introduction}

Greenhouses crops in Italy are made by using prefabricated structures, leaving out the preliminary study of optical and thermal exchanges between the external environment and the greenhouse, dealing with heating and cooling and the effects of air conditioning needed for plant growth [1].

The design and implementation of greenhouses is done without the study of energy exchanges between the external environment inside the greenhouse. Climatic conditions are evaluated only on the plant species planted without verifying the construction parameters of the greenhouse or efficiency of air conditioning systems [2].

As a result of human actions many forest species have become extinct and many more are at risk of extinction. To oppose this loss of forest biodiversity one of the operations most widely used-especially in those areas where the climatic conditions are not optimal-is the multiplication of plant material.
Conservation strategies currently used are in situ and ex situ [3].

The in situ technique requires that the species are preserved in their natural environment, encouraging natural regeneration of wild species or acting through artificial regeneration from seed or transplant in the same area where the seed was taken $[3,4]$.

On the contrary, ex situ conservation takes place outside the natural habitat and is practiced where risk of species' extinction occurs because of events difficult to control, such as climate change or natural disasters [5]. This practice necessarily requires human intervention for collection, storage, and reproduction of different vegetative materials.

The production process of plants is an important step for the conservation of forest species; the seeds are put down in the most suitable conditions in order to promote germination and to protect young plants against biotic and abiotic agents. These conditions can be obtained in greenhouses where it is possible to control solar radiation, temperature, and relative 
humidity of the air and to adapt these parameters to the specific needs of various plant species $[6,7]$.

Greenhouse cover, structural elements, soil, and crop contribute to the solar radiation absorption, and consequently, to the generation of sensible or latent heat [8].

Inside a greenhouse are many interactions that can occur between crop species, climate conditions, and design characteristics of the greenhouse itself. During the design phase, it is necessary to verify the climatic conditions that are found inside the greenhouse as a function of climate zone in which they are installed. This verification is required to ensure a correct design of the greenhouse and also a reduction in energy consumption.

Approximately $20-30 \%$ of the greenhouse on the Italian territory are equipped with heating and cooling. Has been calculated that the energy consumption on the conditioning of greenhouses is about 140,000 TOE (tons of oil equivalent), approximately $90-95 \%$ of global energy demand for the production [9].

From these data it is essential to a detailed study of the energy consumption of the greenhouse. This can be done through the use of TRNSYS 17 dynamic simulator that allows you to verify the energy consumption related to the cultivation of a particular plant species and therefore allows you to change the design of the greenhouse.

The aim of this paper is to identify the most suitable type of greenhouse for the multiplication of plant material in order to preserve forest biodiversity in relation to the specific needs of forest species and climatic conditions in Central Italy. In particular, in this study we created a greenhouse model which allows to check, with TRNSYS, correct climatic conditions inside and the energy consumption related to the cultivation of forest species.

\section{Materials and Methods}

The study was carried out with considering the type "multispan greenhouse" and located in Central Italy.

After the definition of construction parameters, equipments and climatic conditions of the site, microclimatic conditions inside the greenhouse were determined by simulation software TRNSYS 17. As regards the determination of the thermal needs of each species forestry, the phytoclimatic classification of Pavari was considered: according to it, the Italian territory is divided into five climatic zones, characterized by a Latin name-Lauretum, Castanetum, Fagetum, Picetum e Alpinetum - and by an altitudinal and thermal interval. The Latin name refers to the cenosis or species, wild or cultivated by man, which characterizes that specific area [10].

\subsection{Greenhouse Structural Description. Considering the large} size of forest species, the type "multispan greenhouse" - with high height to eaves-was chosen (Figures 1 and 2).

The main dimensional characteristics are the following: length $100 \mathrm{~m}$, width $12.25 \mathrm{~m}$, height to eaves $4.5 \mathrm{~m}$, ridge height $6 \mathrm{~m}$, slope of the roof pitches $22^{\circ}$ (slope $=40 \%$ ), and orientation with the long axis north-south. The cover material

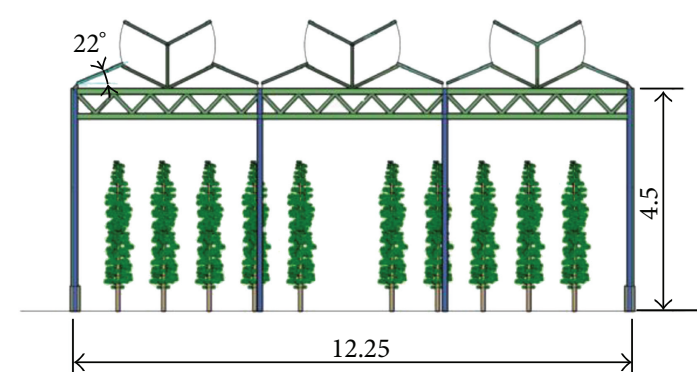

FIGURE 1: Steel and glass greenhouse: SECTION.

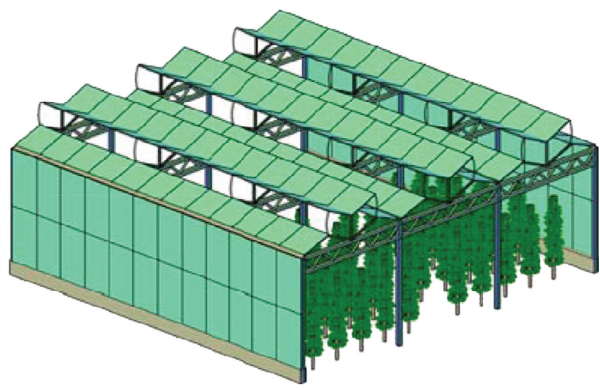

FIGURE 2: Steel and glass greenhouse: AXONOMETRIC VIEW.

is glass since it is the best material for the greenhouse effect and is strong and durable over time.

In order to allow the multiplication of forest species with very different microclimatic needs, particular attention has been paid to the monitoring and control of the inside microclimate.

Greenhouse is equipped with a system of artificial heating to provide energy in winter. Nevertheless, it is more important, in Central Italy, to contain the excess energy in summer because most forest species are sensitive to high temperatures.

Cooling is ensured by natural and mechanical ventilation. The greenhouse is equipped with large openings on the slopes and on the longitudinal walls and axial ventilators placed at the head of it.

The greenhouse is equipped by a system for automatic regulation and control whose aim is to ensure a correct management of the microclimatic conditions. More precisely, it consists of a series of sensors that detect microclimatic internal and external parameters, and of a control unit that processes the data and transmits the changes to the control system.

2.2. Greenhouse Model. The thermal behavior of the greenhouses was studied using dynamic thermal simulation tool, TRNSYS 17. A model, which includes all greenhouse influential variables on microclimate, has been created.

This model includes

(i) detailed design of structures,

(ii) optimizing resources, and

(iii) verification of climatic parameters in greenhouse. 
The simulation of climate parameters of the greenhouse is carried out with a model that calculates the thermal exchanges in nonstationary conditions [11]. Depending on the parameter, one can highlight energy waste and improve the design of the greenhouse. The created model can be applied in any type of greenhouse changing design parameters in the TYPE 56.

The model was built using the simulation program TRNSYS Studio. The first step concerns the construction of a building multizone, which is divided into multiple steps in which the user enters the data relating to the building and its location in space [12]. TRNSYS provides a daily evaluation on the air conditioning system in the greenhouse in response to the climatic conditions of the area in which greenhouse is located.

The climatic parameters affecting the growth of greenhouse plants are [13]

(i) radiation entering the greenhouse in the ultraviolet band (290 to $380 \mathrm{~nm})$, visible ( 380 to $760 \mathrm{~nm}$ ) and near infrared $(760-3000 \mathrm{~nm})$,

(ii) air, soil and plants temperature,

(iii) air humidity, and

(iv) air composition (particularly the concentration of $\mathrm{CO}_{2}$ ).

Solar radiation inside the greenhouse is less than the outer coating material which reflects and absorbs solar radiation; one also needs a ventilation system that ensures the air movement between the plants and facilitates the transpiration; the lower is the air movement, and the smaller is the concentration gradient of $\mathrm{CO}_{2}$.

It is necessary to assess the detailed exchange of energy between internal and external part to have accurate values of climatic parameters in the greenhouse and to study the temperatures that influence the thermal freight exchange [1417]:

(i) air temperature,

(ii) soil temperature (or substrate for soilless),

(iii) plants temperature, and

(iv) temperature of the greenhouse cover.

In order to calculate the heat balance in emissions, it is fundamental to examine the individual energy input (Figure 3).

Energy balance equation:

$$
\begin{aligned}
R_{\mathrm{i}}+R_{\mathrm{ac}}= & R T_{\mathrm{g}, \mathrm{sky}}+R T_{\mathrm{g}, \mathrm{atm}}+R T_{\mathrm{p}, \mathrm{sky}}+R T_{\mathrm{p}, \mathrm{atm}}+R T_{\mathrm{c}, \mathrm{sky}} \\
& +R T_{\mathrm{c}, \mathrm{atm}}+T_{\mathrm{c}}+V+\Delta E_{\mathrm{g}}+S_{\mathrm{g}},
\end{aligned}
$$

where

$$
T=K S\left(T_{\mathrm{i}}-T_{\mathrm{e}}\right),
$$

$K$ is thermal transmittance $\left(\mathrm{W} \mathrm{m}^{-2} \mathrm{~K}^{-1}\right) ; S$ is wall surface $\left(\mathrm{m}^{2}\right) ; T_{\mathrm{i}}$ is internal temperature $\left({ }^{\circ} \mathrm{C}\right)$; and $T_{\mathrm{e}}$ is external temperature $\left({ }^{\circ} \mathrm{C}\right)$.

$$
E_{v}=V\left(H_{\mathrm{i}}-H_{\mathrm{e}}\right),
$$

$E_{v}=$ energy lost for ventilation $\left(\mathrm{KJ} \mathrm{h}^{-1}\right) ; V=$ flow rate of ventilation $\left(\mathrm{Kg}\right.$ DryAir $\left.^{-1}\right) ; H_{\mathrm{i}}=$ internal air enthalpy$\left(\mathrm{KJ} \mathrm{Kg} \mathrm{DryAir}{ }^{-1}\right) ; H_{\mathrm{e}}=$ external air enthalpy (KJ Kg Dry$\mathrm{Air}^{-1}$ ).

The enthalpy $H$ (KJ Kg DryAir ${ }^{-1}$ ) of a $\mathrm{Kg}$ of air, at temperature $t\left({ }^{\circ} \mathrm{C}\right)$ and with a water content, in the form of water, equal to $x$ ( $\left.\mathrm{Kg} \mathrm{Kg} \mathrm{DryAir}{ }^{-1}\right)$ is obtained from

$$
H=1.005 t+x(2499.5+2.005 t),
$$

$x\left(\mathrm{Kg} \mathrm{Kg} \mathrm{DryAir}^{-1}\right)$ represents the water vapor contained in the air and can be determined through the psychrometric diagram or with the following formula:

$$
x=0.6215 \frac{P_{\mathrm{H}_{2} \mathrm{O}}}{P-P_{\mathrm{H}_{2} \mathrm{O}}},
$$

$P=1.013\left(\mathrm{Kg} \mathrm{cm}^{-2}\right)$ atmospheric pressure; $P_{\mathrm{H}_{2} \mathrm{O}}=$ vapor pressure of the air, expressed in $\mathrm{Kg} \mathrm{cm}^{-2}$ at the temperature $T(\mathrm{~K})$ and at relative humidity UR (\%);

$$
\begin{aligned}
P_{\mathrm{H}_{2} \mathrm{O}}= & 1.41 \times 10^{10} e^{(-3928.5 /(T-41.5))} \times \mathrm{UR},(\mathrm{Pa}), \\
R T_{12}= & \sum_{\lambda=2.5 \mu \mathrm{m}}^{\lambda=20 \mu \mathrm{m}} \varepsilon_{12}(\lambda) \times \tau_{a}(\lambda) \times \frac{C_{1}}{\lambda^{5}} \\
& \times\left[\frac{1}{e^{\mathrm{C}_{2} / \lambda \times T_{1}}-1}-\frac{1}{e^{\mathrm{C}_{2} / \lambda \times T_{2}}-1}\right] \times \Delta \lambda
\end{aligned}
$$

$R T_{12}=$ radiated radiation $\left(\mathrm{W} \mathrm{m}^{-2}\right) ; \lambda=$ wavelength $(\mu \mathrm{m}) ;$ $T$ = absolute temperature (K); $C_{1}=3.74 \cdot 10^{8}\left(\mathrm{~W} \mu \mathrm{m}^{4} \mathrm{~m}^{-2}\right)$; $C_{2}=14385(\mathrm{~K} \mu \mathrm{m}) ; \tau_{a}(\lambda)=$ transmittance of the atmosphere at the wavelength $\lambda ; \varepsilon_{(\lambda)}=$ monochromatic emissivity of the object at the wavelength $\lambda$.

The TRNSYS is commonly used to simulate transient heat transfer for design and control of power systems exploiting renewable energy sources. Another frequent use of software is now on the energy certification for homes, offices, shops, restaurants, and industries. In this sense the present work is an example of using the software for agricultural systems [18]. The structure is a multispan greenhouse with high height to eaves, used as a greenhouse for growing flowers and plants. It is covered with glass cover horizontal beam pattern and small flat foot north-south. The approach of the model was carried out by using the program TRNSYS Simulation Studio. The first step concerns the construction of a building multizone, which is divided into multiple steps in which the user enters the data relating to the building and its location in space [12]. The data required by the software at this stage will be used for the automatic construction of the project and its connections between the components.

During construction of the project there is also the source of meteorological data that will be used in the simulation. This is indeed a link with the Type 109 (Weather Data Processor) and in the present study, the meteorological station of Rome Fiumicino (Airport) was selected. The outline of the project is in (Figure 4), where 


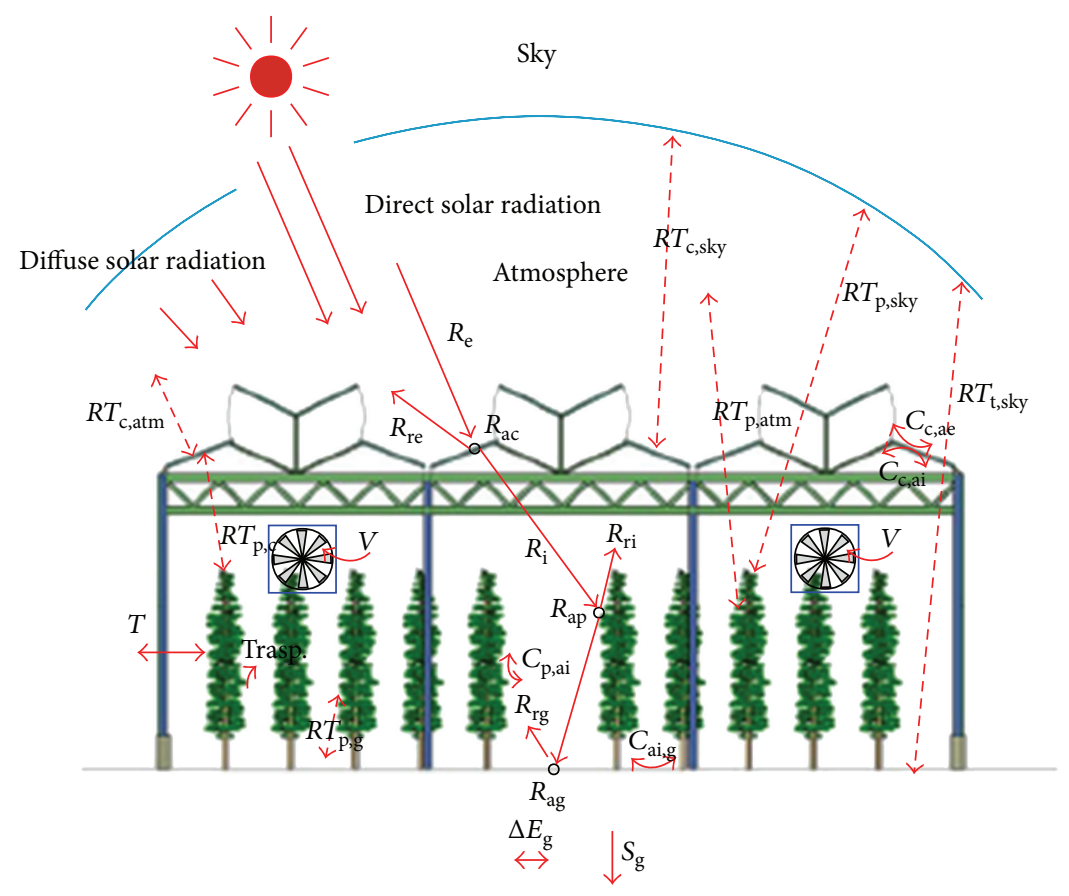

FigUre 3: Heat balance in a greenhouse.

weather date: weather generator

psychrometrics: processor psychrometric

sky Temp: CPU temperature sky

radiation: radiation converter

greenhouse: Greenhouse (Type 56)

nat. Vent. 1 and 2: controllers of ventilation

turn: unit converters

charts: Online Plotter.

\section{Results}

3.1. Simulation Results. The purpose of the simulation is to check the temperatures inside the greenhouse related to external climatic parameters and the type of construction of the greenhouse itself. The required energy for optimal climate conditioning is based on such calculation. These values in fact are calculated in order to maintain a steady temperature of 20 degrees which is considered suitable for the cultivation of a wide range of plant species. The results are shown in the chart (Figures 5, 6, 7, 8 and 9):

The solar radiation arrives in the greenhouse and affects the inside temperature. In particular the characteristic constructive of the greenhouse is $97 \%$ of the radiation incident, reaches the ground, and increases on the internal temperature (Figure 7).

In Figure 6 the solar radiation inside the greenhouse is compared with the incident one. It can be seen that the low resistance of the structure results to be an advantage in winter, even if energy consumption for cooling is higher.
During cold months the internal radiation is almost equal to the outside, while in summer transmission of solar radiation falls on the most important reflection of the glass. This is due to the increased presence of direct radiation and different angles of incidence.

During the winter months the trend of the indoor temperature is almost identical to that of the external solar radiation and the structure has a low thermal capacity (infiltration losses of 1/h) (Figure 9), where

\section{$T_{\text {Greenhouse }}$ : inside room temperature}

$Q_{\text {Heat }}$ : required heating, the rate at which energy must be supplied to the device in order to heat the air to its outlet temperature, including the effects of losses and conversion inefficiencies.

$Q_{\text {Cool }}$ : rate of energy removed with the cooling system.

Moreover, the amount of heat to be provided or removed by heating and cooling was connected to the printer to obtain the annual energy needs for heating and cooling:

$$
\begin{aligned}
& Q_{\text {Heat }}=1,44 E+23 \mathrm{~kJ} \mathrm{~h}^{-1}, \\
& Q_{\text {Cool }}=2,25 E+23 \mathrm{~kJ} \mathrm{~h}^{-1} .
\end{aligned}
$$

It can be seen that the energy demand for cooling is higher than that for heating [14]. This is due to the latitude where the greenhouse is located, characterized by very rigid winters and hot summers. The technology normally used in greenhouses for cooling, as shown in the chart above, is from an energy point of view very expensive. The graphic represents a 


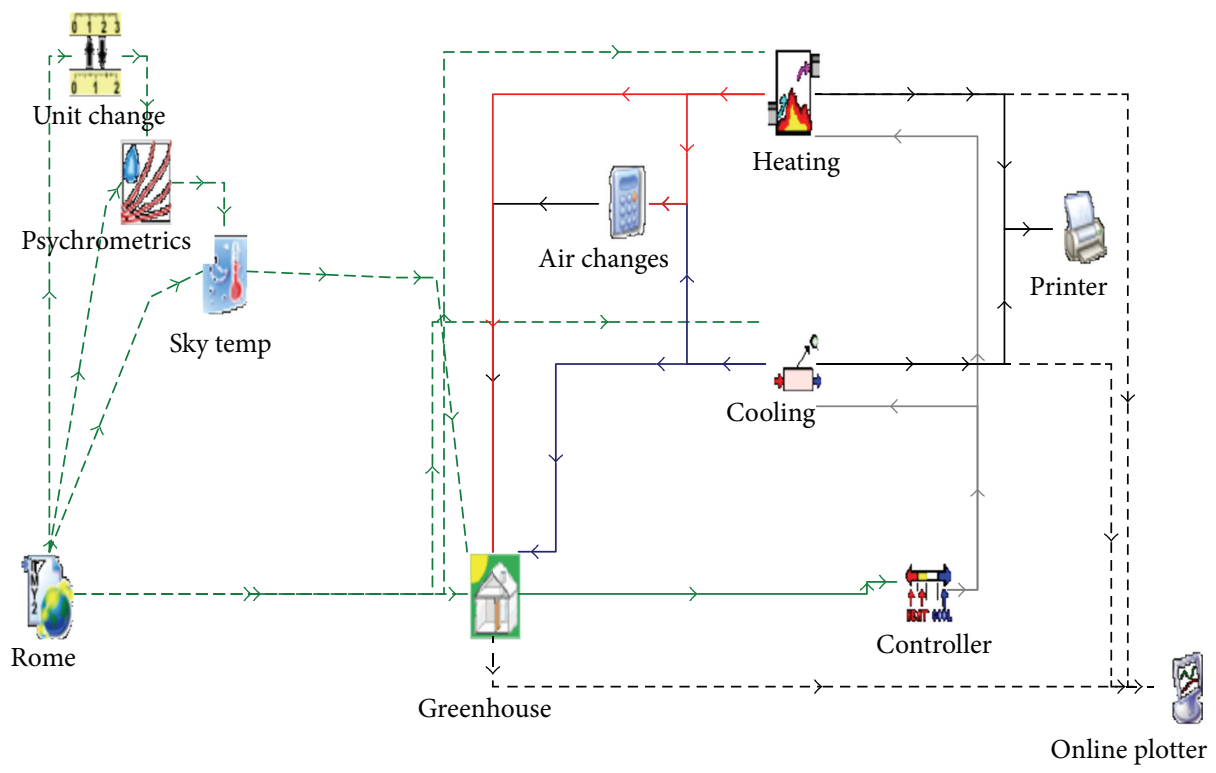

FIGURE 4: Air conditioning system diagram with TRNSYS.

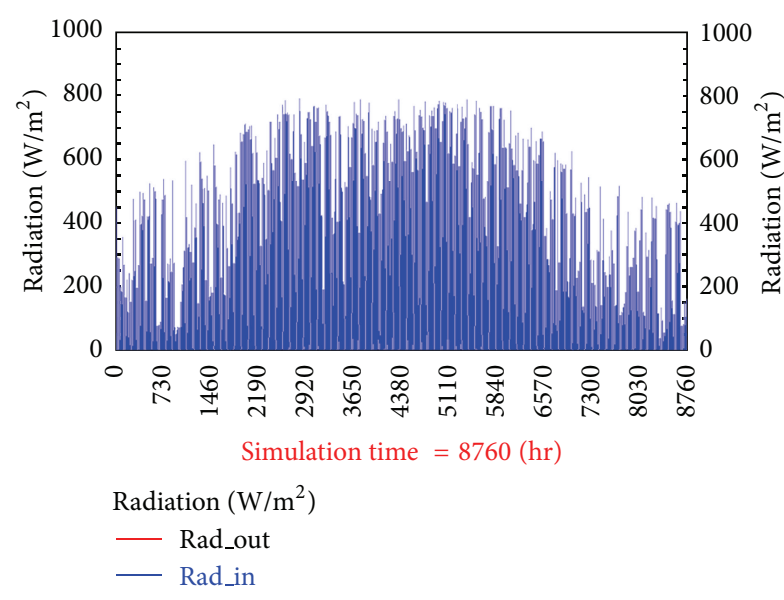

FIGURE 5: Simulation of annual solar radiation inside the greenhouse $\left(\mathrm{W} / \mathrm{m}^{2}\right)$.

constant value of $Q_{\text {Cool }}$ for the period July-August, even if the temperature inside the greenhouse undergoes changes.

An analysis of the chart is highlighting the need to rationalize the climate inside the greenhouse. This can be achieved

(i) either through the use of a more precise control systems, such as PID;

(ii) through more sustainable air conditioning systems. The latter using heating and cooling floor system powered by a geothermal heat pump or conventional pump;

(iii) or improving the greenhouse insulation and ventilation systems.

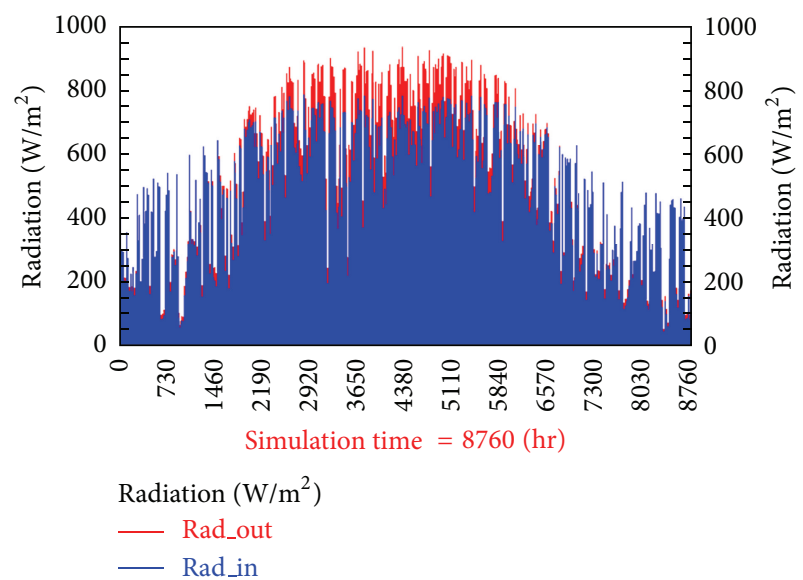

FIgURE 6: Simulation of annual solar radiation inside the greenhouse $\left(\mathrm{W} / \mathrm{m}^{2}\right)$ in blue and external red.

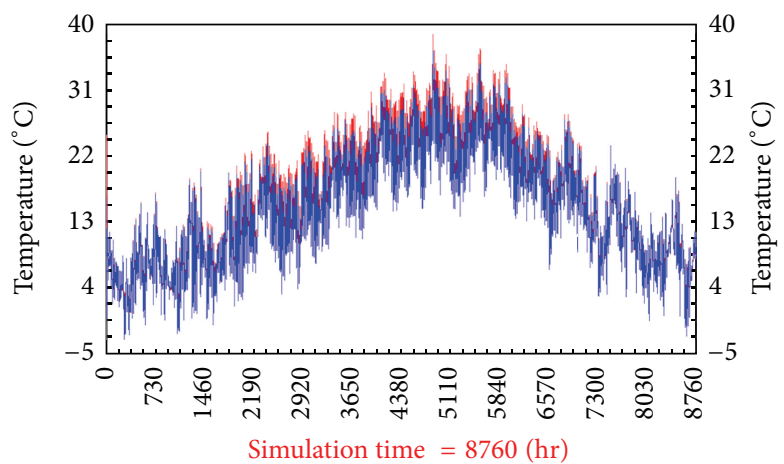

Temperature $\left({ }^{\circ} \mathrm{C}\right)$

- Temp_in

- Temp_out

FiguRE 7: Simulation of annual temperatures. 


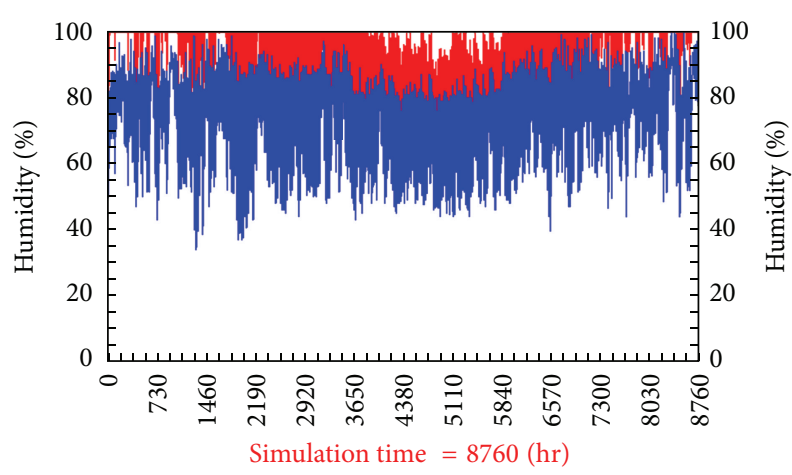

Humidity (\%)

— Humid_in

_ Humid_out

FIGURE 8: Simulation of annual relative humidity (\%).

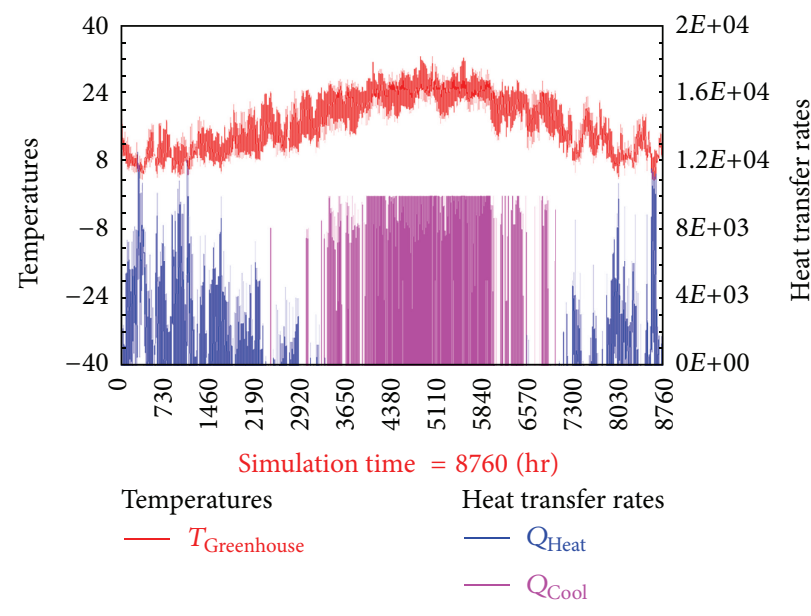

FIGURE 9: Chart of greenhouse climate simulation.
Furthermore, energy needs in winter (heating) and in summer (cooling) were calculated in order to reduce seasonal fluctuations in the air temperature.

These values are compatible with the needs of forest plants included in the range of phytoclimatic Lauretum classification of Pavari.

It has to be underlined that the control systems for heating and cooling should be used-to a greater extent-for other forest species.

The greenhouse model created with the TRNSYS allows use for various applications, that is small changes of parameters allow you to use it for the simulation of different tree species and climatic zones. Turns out to be an important tool for the design of greenhouses. The model created ensures, in fact, a sustainable building, from the point of view of energy, while minimizing energy consumption.

Thanks to a prior verification of heat exchanges achievable between the inside and the outside of the greenhouse is possible to intervene in the construction phase through the modification of the constructive aspects.

\section{Nomenclature}

Alphabetic Symbols

$R:$ Global solar radiation $\left[\mathrm{MJ} \mathrm{m}^{-2} \mathrm{~d}^{-1}\right]$

$R T$ : Energy lost by radiation $\left[\mathrm{MJ} \mathrm{m}^{-2} \mathrm{~d}^{-1}\right]$

$C$ : Energy exchanged by convection $\left[\mathrm{MJ} \mathrm{m}{ }^{-2} \mathrm{~d}^{-1}\right.$ ]

$T$ : Energy lost by transmission [MJ m ${ }^{-2} \mathrm{~d}^{-1}$ ]

$V:$ Energy lost by ventilation $\left[\mathrm{MJ} \mathrm{m}^{-2} \mathrm{~d}^{-1}\right]$

$T R$ : Plant transpiration $\left[\mathrm{MJ} \mathrm{m}^{-2} \mathrm{~d}^{-1}\right]$

$S: \quad$ Energy transferred by conduction in the deep layers $\left[\mathrm{MJ} \mathrm{m}^{-2} \mathrm{~d}^{-1}\right]$

E: Thermal storage $\left[\mathrm{MJ} \mathrm{m}^{-2} \mathrm{~d}^{-1}\right]$.

\section{Subscripts}

identified in order to multiply forest plants for biodiversity conservation. It is a multispan greenhouse covered with glass and high height to the eaves. The Energy balance, between the input and output of energy, was carried out for this specific type of greenhouse. This goal was reached by the simulation in TRNSYS and with specific regard to locations in Central Italy. The results obtained in the simulation show the following values for the principal microclimatic parameters:

(i) solar radiation: $300-600 \mathrm{~W} / \mathrm{m}^{2}$ in winter months and $600-800 \mathrm{~W} / \mathrm{m}^{2}$ in summer months;

(ii) air temperature: $10-20^{\circ} \mathrm{C}$ in winter months and $20-$ $34^{\circ} \mathrm{C}$ in summer months;

(iii) relative humidity: $85-95 \%$ in winter months and $75-$ $85 \%$ in summer months.

$\begin{array}{ll}\text { e: } & \text { External } \\ \text { re: } & \text { Reflected external } \\ \text { ac: } & \text { Absorbed by the cover } \\ \text { i: } & \text { Internal } \\ \text { ri: } & \text { Reflected internal } \\ \text { ap: } & \text { Absorbed by the plants } \\ \text { rg: } & \text { Reflected from the ground } \\ \text { ag: } & \text { Absorbed by the ground } \\ \text { c: } & \text { Cover film } \\ \text { p: } & \text { Plants } \\ \text { G: } & \text { Ground } \\ \text { ia: } & \text { Indoor air } \\ \text { oa: } & \text { Outdoor air } \\ \text { atm: Atmosphere } \\ \text { sky: Vault of heaven. }\end{array}$

e: External

re: Reflected external

ac: Absorbed by the cover

i: Internal

ri: Reflected internal

ap: Absorbed by the plants

rg. - Reflected from the ground

ag: Absorbed by the ground

c: Cover film

p: Plants

G: Ground

a: Indoor air

atm: Atmosphere

sky: Vault of heaven. 


\section{References}

[1] M. Carlini and S. Castellucci, "Modelling and simulation for energy production parametric dependence in greenhouses," Mathematical Problems in Engineering, vol. 2010, Article ID 590943, 28 pages, 2010.

[2] M. Carlini, S. Castellucci, M. Guerrieri, and T. Honorati, "Stability and control for energy production parametric dependence," Mathematical Problems in Engineering, vol. 2010, Article ID 842380, 21 pages, 2010.

[3] B. Piotto, V. Giancanelli, and S. Ercoles, La conservazione ex situ della biodiversità delle specie vegetali spontanee e coltivate in Italia. Stato dellarte, criticità e azioni da compiere, Istituto Superiore per la Protezione e la Ricerca (ISPRA '10), Rome, Italy, 2010.

[4] L. Thomson, L. Graudal, and E. Kjær, "Conservation of genetic resources in their natural environment: in managed natural forests and protected areas (in situ)," in Forest Genetic Resources Conservation and Management, FAO, DFSC, and IPGRI, Eds., vol. 2, pp. 1-3, International Plant Genetic Resources Institute, Rome, Italy, 2001.

[5] W. Amaral and A. Yanchuk, "Integrated approaches for ex situ conservation and use of forest genetic diversity: in plantations and genebanks (ex situ)," in Forest Genetic Resources Conservation and Management, FAO, DFSC, and IPGRI, Eds., vol. 3, pp. 1-3, International Plant Genetic Resources Institute, Rome, Italy, 2004.

[6] A. Marucci and A. Cappuccini, "The characteristics of the greenhouses for the conservation of forest biodiversity in the Mediterranean environment," in Proceedings of the International Conference on "The Role of Biobanks for Research and Protection of Forest Biodiversity" (MFDB '12), University of Tuscia, Viterbo, Italy, April 2012.

[7] P. Piussi, Selvicoltura Generale, UTET, 1994.

[8] A. Mistriotis, C. Arcidiacono, P. Picuno, G. P. A. Bot, and G. Scarascia-Mugnozza, "Computational analysis of ventilation in greenhouses at zero- and low-wind-speeds," Agricultural and Forest Meteorology, vol. 88, no. 1-4, pp. 121-135, 1997.

[9] M. Carlini, T. Honorati, and S. Castellucci, "Photovoltaic greenhouses: comparison of optical and thermal behaviour for energy savings," Mathematical Problems in Engineering, vol. 2012, Article ID 743764, 10 pages, 2012.

[10] Y. Rouphael, M. T. Cardarelli, N. Ajouz, A. Marucci, and G. Colla, "Estimation of eggplant leaf number using thermal time model," Journal of Food, Agriculture and Environment, vol. 8, no. 2, pp. 847-850, 2010.

[11] M. Carlini, M. Villarini, S. Esposto, and M. Bernardi, "Performance analysis of greenhouses with integrated photovoltaic modules," in Proceedings of the International Conference on Computational Science and Its Applications (ICCSA '10), vol. 6017 of Lecture Notes in Computer Science, pp. 206-214, 2010.

[12] S. Holst, "Heating load of a building model in TRNSYS with different heating systems," ZAE Bayern, Abt. 4, TRNSYS-User Day, Stuttgart, Germany, 1993.

[13] J. E. Braun and J. C. Mitchell, "Solar geometry for fixed and tracking surfaces," Solar Energy, vol. 31, no. 5, pp. 439-444, 1983.

[14] D. T. Reindl, W. A. Beckman, and J. A. Duffie, "Diffuse fraction correlations," Solar Energy, vol. 45, no. 1, pp. 1-7, 1990.

[15] A. Marucci and B. Pagniello, "Simulation of the growth and the production of the tomato in typical greenhouses of the Mediterranean environment," Journal of Food, Agriculture and Environment, vol. 9, no. 3-4, pp. 407-411, 2011.
[16] E. Campiglia, G. Colla, R. Mancinelli, Y. Rouphael, and A. Marucci, "Energy balance of intensive vegetable cropping systems in central Italy," Acta Horticulturae, vol. 747, pp. 185-191, 2007.

[17] A. Marucci, E. Campiglia, G. Colla, and B. Pagniello, "Environmental impact of fertilization and pesticide application in vegetable cropping systems under greenhouse and open field conditions," Journal of Food, Agriculture and Environment, vol. 9, no. 3-4, pp. 840-846, 2011.

[18] H. Laukamp, "Inverter for photovoltaic systems (in German). User-written TRNSYS source code," Fraunhofer-Institute für Solare Energiesysteme, Freiburg im Breisgau, Germany, 1988. 


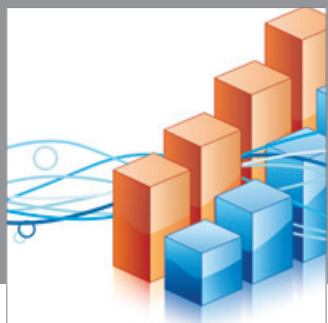

Advances in

Operations Research

mansans

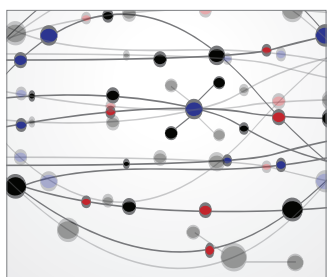

The Scientific World Journal
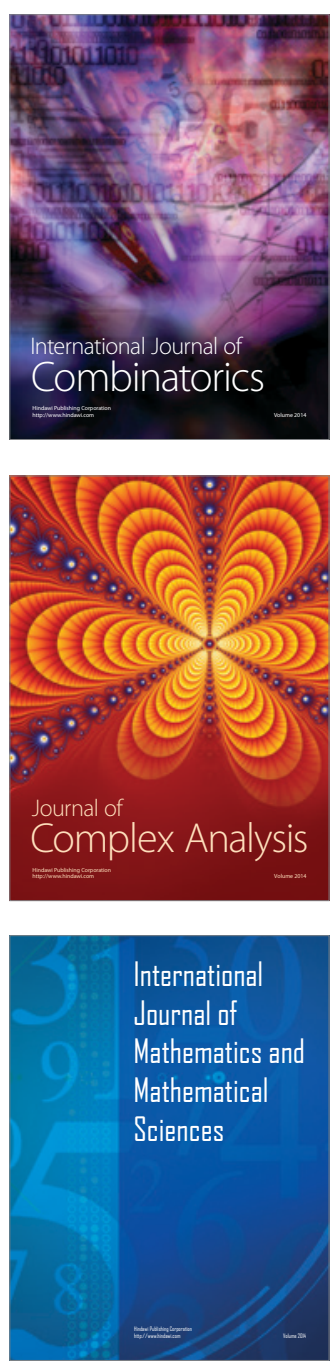
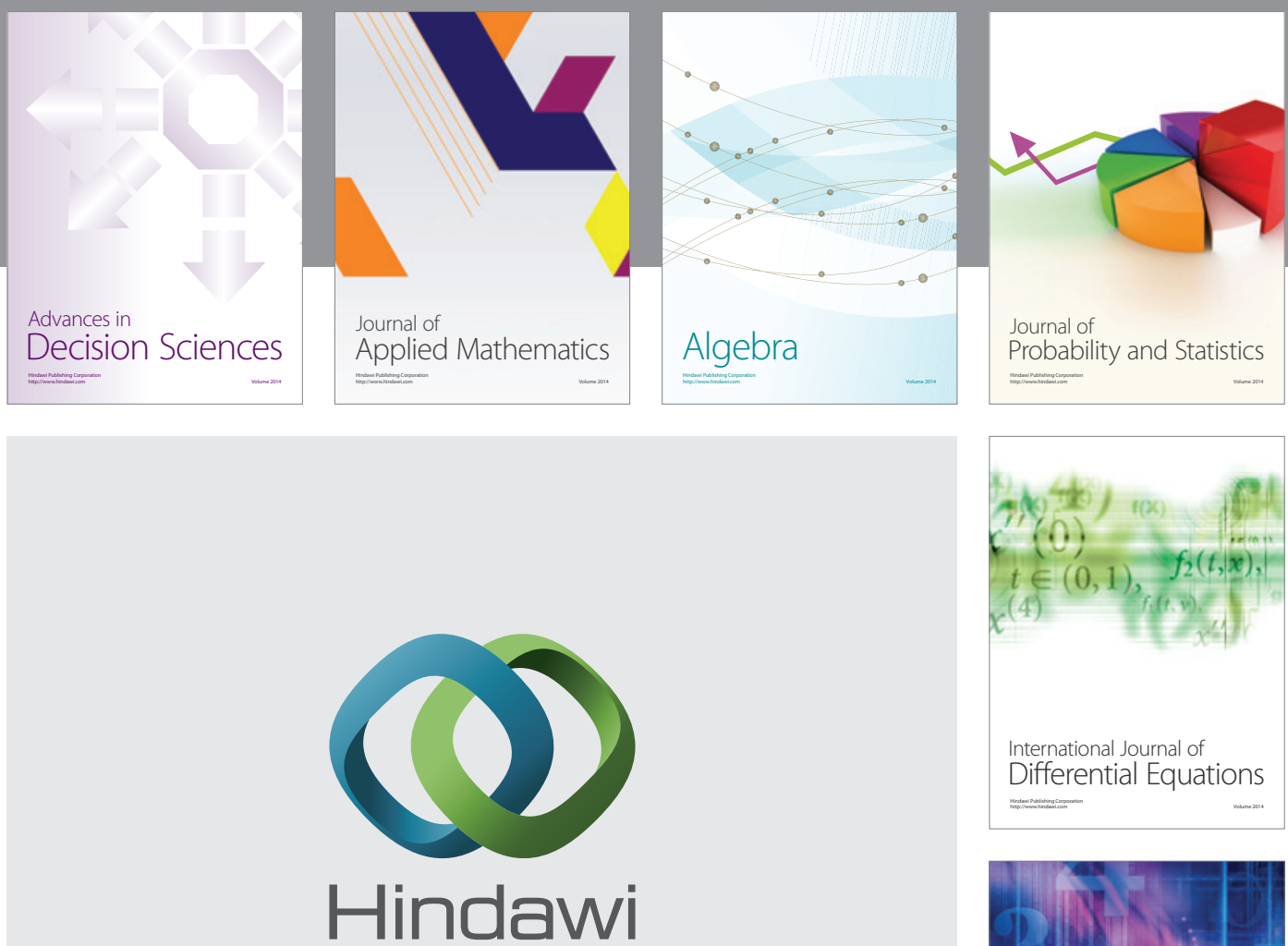

Submit your manuscripts at http://www.hindawi.com
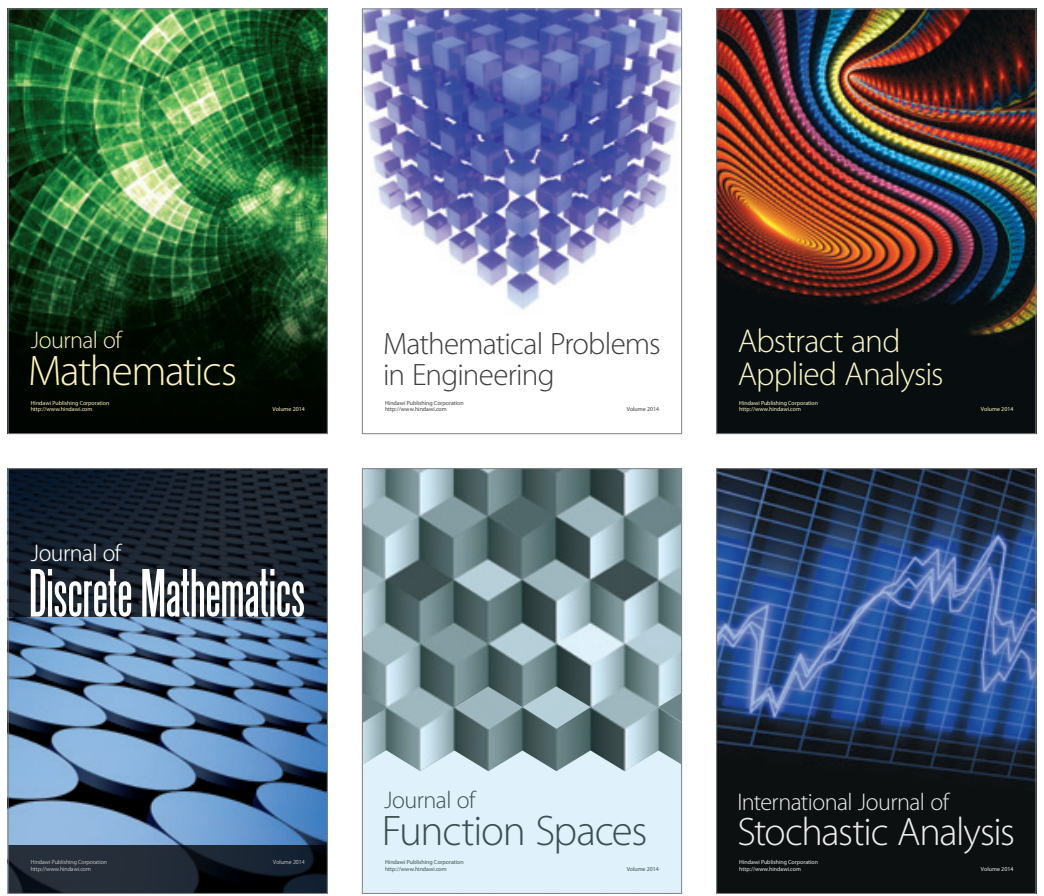

Journal of

Function Spaces

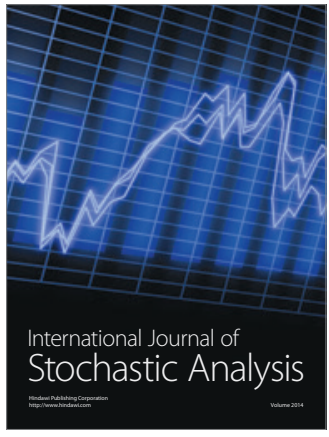

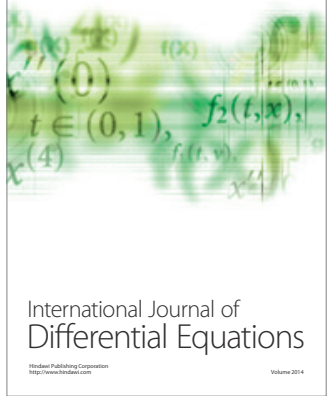
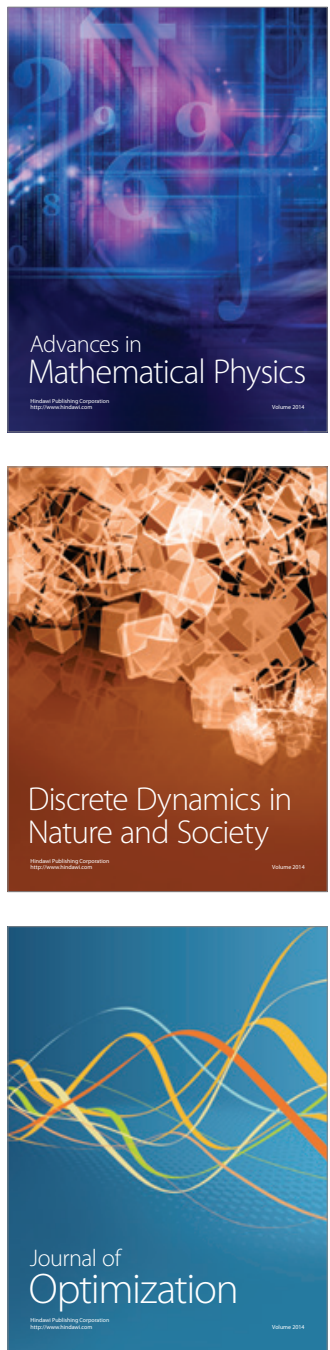